\title{
Patient Factors Associated with Prescribing of Iron for IV Administration: A Descriptive Study
}

\author{
Thomas Brownlee, Deonne Dersch-Mills, Ginny Cummings, Tanya Fischer, Rhonda Shkrobot, Jeremy Slobodan, \\ and Jenny Wichart
}

Can J Hosp Pharm. 2021;74(1):50-6

\begin{abstract}
Background: IV administration of iron is appropriate for the treatment of iron deficiency anemia (IDA) when orally administered iron has not been effective, tolerated, or clinically appropriate. In Calgary, Alberta, high levels of IV iron utilization required review, because of significant health care resource utilization, high cost, and reduced accessibility.

Objectives: The primary objective was to describe the population of adult patients in Calgary with estimated glomerular filtration rate greater than or equal to $30 \mathrm{~mL} / \mathrm{min} / 1.73 \mathrm{~m}^{2}$ for whom IV iron was dispensed from acute care facilities, in terms of pretreatment laboratory data, previous use of oral iron, and treatment location, as well as to characterize dose and product selection for IV iron. The secondary objective was to determine the proportion of inpatients whose treatment was in alignment with the Toward Optimized Practice clinical practice guideline for IDA.
\end{abstract}

Methods: A retrospective review of electronic charts was used to obtain data about patients with a first dose of IV iron dispensed in Calgary hospitals between March 1 and December 31, 2018. The data were analyzed descriptively.

Results: A total of 1352 patients met the inclusion criteria. These patients received a total of 3532 doses of IV iron, $97.1 \%$ of which were iron sucrose, at a median of $300 \mathrm{mg}$ per infusion. Laboratory indices assessed before the first infusion were hemoglobin (mean 92, standard deviation [SD] $19.6 \mathrm{~g} / \mathrm{L}$ ), mean corpuscular volume (mean 81 [SD 10.3] fL), and ferritin (median 18 [interquartile range 9-48] $\mu \mathrm{g} / \mathrm{L}$ ). Among the included patients, $233(17.2 \%)$ had oral iron dispensed within 90 days before their first IV dose of iron. Only 146 (20.1\%) of the 726 inpatients had treatment that was in alignment with the Toward Optimized Practice IDA guideline.

Conclusions: There was substantial variation in baseline hemoglobin, mean corpuscular volume, and ferritin, and in the use of oral iron before initiation of IV iron treatment. Provision of educational tools and stewardship initiatives may help in ensuring alignment of iron prescribing with current guidelines.

Keywords: iron deficiency anemia, parenteral iron, iron sucrose, stewardship

\section{RÉSUMÉ}

Contexte : L'administration de fer par intraveineuse (IV) convient au traitement de l'anémie ferriprive lorsque son administration par voie orale n'a pas été efficace, tolérée ou appropriée d'un point de vue clinique. À Calgary (Alberta), il a fallu réviser les quantités de fer administrées par IV en raison de la mobilisation importante des ressources de soins de santé et des coûts élevés que cela exigeait ainsi que de l'accessibilité réduite au produit.

Objectifs : L'objectif principal consistait à décrire la population de patients adultes, dont le taux estimé de filtration glomérulaire était supérieur ou égal à $30 \mathrm{~mL} / \mathrm{min} / 1,73 \mathrm{~m}^{2}$ et à qui on administrait du fer par IV dans des installations de soins intensifs de Calgary. La description devait se faire en termes de données de laboratoire préalables au traitement, d'administration antérieure de fer par voie orale et de lieu du traitement; il s'agissait aussi de décrire la dose et la sélection du produit pour l'administration de fer par IV. L'objectif secondaire consistait à déterminer la proportion de patients hospitalisés, dont le traitement s'alignait sur les directives de pratique clinique Toward Optimized Practice relatives à l'anémie ferriprive.

Méthodes : Un examen rétrospectif des tableaux électroniques a permis d'obtenir des données sur les patients, ayant reçu une première dose de fer par IV dans les hôpitaux de Calgary, entre le $1^{\text {er }}$ mars et le 31 décembre 2018. Les données ont fait l'objet d'une analyse descriptive.

Résultats : Au total, 1352 patients répondaient au critère d'inclusion. Ils ont reçu 3532 doses de fer par IV, dont 97,1 \% de saccharose de fer à raison d'une médiane de $300 \mathrm{mg}$ par perfusion. Les indices de laboratoire évalués avant la première perfusion concernaient l'hémoglobine (moyenne 92, écart-type [ET] 19,6 g/L), le volume corpusculaire moyen (moyenne 81 [ET 10,3] fL) et la ferritine (moyenne 18 [écart interquartile 9-48] $\mu \mathrm{g} / \mathrm{L}$ ). Parmi les patients de l'étude, 233 (17,2 \%) avaient reçu du fer par voie orale 90 jours avant la première dose de fer administrée par IV. Seuls $146(20,1 \%)$ des 726 patients hospitalisés avaient reçu un traitement conforme aux directives de pratique clinique Toward Optimized Practice relatives à l'anémie ferriprive.

Conclusions : On a constaté une variation importante de l'hémoglobine de base, du volume corpusculaire moyen et de la ferritine, ainsi que de I'utilisation du fer par voie orale avant le début du traitement par IV. Des outils pédagogiques et des initiatives de gestion pourraient aider à assurer I'alignement de la prescription de fer sur les directives actuelles.

Mots-clés : anémie ferriprive, fer administré par voie parentérale, fersaccharose, gérance 


\section{INTRODUCTION}

Iron deficiency anemia (IDA) is estimated to affect $1 \%$ to $2 \%$ of adults, accounting for approximately $50 \%$ to $80 \%$ of anemia cases worldwide. ${ }^{1-3}$ Common presentations include symptoms of anemia, such as fatigue, skin pallor, and shortness of breath, as well as signs that are more specific to iron deficiency, including pica, restless legs, and hair loss or damage. ${ }^{2}$ Complications associated with IDA include impaired quality of life, decreased work productivity, depression, and reduced cognitive functioning. ${ }^{2,4}$ The diagnosis is based on hemoglobin $(\mathrm{Hb})$, mean corpuscular volume (MCV), and ferritin values below designated levels, which vary slightly among guidelines. ${ }^{1,2,5,6}$ Ferritin is the most accurate marker for detecting iron deficiency; however, other iron studies can be considered when the results of ferritin testing are indeterminate. ${ }^{5}$

Pharmacologically, the mainstays of treatment for iron deficiency are the orally administered iron salts: ferrous sulfate, gluconate, and fumarate. ${ }^{1,2,4,7}$ Oral ferrous salts are widely available, inexpensive, and safe; however, they are associated with a high rate of gastrointestinal adverse effects, often resulting in nonadherence. ${ }^{4,5}$ Newer formulations of oral iron, including iron polysaccharide complex and heme iron polypeptide, may be better tolerated but are more expensive and no more effective in correcting anemia than other iron salts. ${ }^{6,8}$

IV administration of iron is indicated when blood loss exceeds the absorptive capacity for iron, which may occur with uterine bleeding, hemodialysis, or iron malabsorption syndromes or when oral iron is not tolerated or is ineffective. ${ }^{1,2,7,9}$ It can also be considered when $\mathrm{Hb}$ concentration is less than $60 \mathrm{~g} / \mathrm{L}$ and rapid correction of iron stores is needed, or in circumstances when transfusion is contraindicated. ${ }^{6,710} \mathrm{IV}$ iron administration has the advantages of fewer gastrointestinal side effects, improved adherence, and more rapid iron replacement and correction of anemia. ${ }^{4,11}$ However, data are insufficient to suggest a benefit over oral iron in terms of important clinical outcomes, such as mortality, blood transfusion requirements, and length of hospital stay. ${ }^{12-15}$ Other potential concerns with IV iron include infusion reactions, the discomfort and inconvenience of IV administration, increased drug cost, and higher utilization of health care resources. ${ }^{4,6}$

In Alberta, IV iron products are becoming more frequently prescribed, with expenditures increasing 78\% between 2015 and 2019 and representing $4.6 \%$ of the provincial acute care drug budget in the 2018/19 fiscal year (unpublished data). IV iron administration accounts for approximately $20 \%$ of visits to Calgary Zone Day Medicine departments and has been trending upward in recent years. ${ }^{16}$ Initiatives to reduce the use of blood transfusions may have been a factor contributing to this increase. ${ }^{16}$ Interest in optimizing anemia management prompted Alberta Health Services (AHS) to host the Iron Summit Conference in 2017, which aimed to identify gaps and opportunities and propose solutions to the management of IDA in the Calgary Zone. ${ }^{16}$ During the summit it was suggested that some referrals for IV iron may not have been appropriate. ${ }^{16}$ Furthermore, in cases of drug shortages from manufacturers, many medical specialists reported inconsistencies in their ability to access IV iron because of limited availability of outpatient appointments. ${ }^{16}$ In March 2018, the Toward Optimized Practice (TOP) clinical practice guideline for IDA was published to provide prescribing guidance for primary care and emergency department practitioners in Alberta and thus support consistent management of IDA. ${ }^{6,16}$ The TOP, now known as the Accelerating Change Transformation Team or ACTT, is a program supported by the Alberta Medical Association that enhances practice through provision of clinical practice guidelines, among other initiatives, primarily directed toward primary care physicians. Calgary clinicians have shown support for the concept of incorporating the TOP IDA treatment algorithm into eligibility criteria for access to parenteral iron. ${ }^{6,16}$

It is currently unknown whether certain patient-specific factors contribute to potential gaps in optimal prescribing of IV iron in Calgary. The overall objective of this study was to describe the characteristics of adult patients receiving IV iron to better understand prescribing patterns and identify target areas where initiatives to optimize iron usage could be focused. The TOP IDA clinical practice guideline was used as the basis for comparison to identify these target areas. More specifically, the primary objective was to describe adult patients with estimated glomerular filtration rate (eGFR) greater than or equal to $30 \mathrm{~mL} / \mathrm{min} / 1.73 \mathrm{~m}^{2}$ for whom IV iron was dispensed, in terms of their pretreatment laboratory data, previous use of oral iron, and treatment location, as well as to characterize dose and product selection for IV iron. The secondary objective was to determine the proportion of inpatients whose treatment was in alignment with the TOP IDA clinical practice guideline.

\section{METHODS}

\section{Study Design}

A retrospective chart review was conducted in adult patients for whom IV iron was dispensed at any of the 4 adult tertiary care hospitals in Calgary in 2018. These facilities provide inpatient and ambulatory health care services to more than 1.6 million people from Calgary and the surrounding area. ${ }^{17}$

\section{Study Population}

Patients who were 18 years of age or older, had an eGFR greater than or equal to $30 \mathrm{~mL} / \mathrm{min} / 1.73 \mathrm{~m}^{2}$, and had their first dose of IV iron dispensed between March 1 and December 31,2018, were included in the study. Participants were drawn from both inpatient and ambulatory care settings. To determine which patients received their first dose of IV iron 
on or after March 1, 2018, all IV iron doses dispensed to the target population between January 1 and December 31, 2018, were reviewed, and patients who received doses between January 1 and February 28, 2018, were excluded.

Chronic kidney disease is known to contribute to iron deficiency and is a well-recognized indication for IV iron; however, the TOP IDA guideline excludes patients with chronic kidney disease from its recommendations, and there are local practice documents for this patient group. ${ }^{6}$ As such, patients with eGFR less than $30 \mathrm{~mL} / \mathrm{min} / 1.73 \mathrm{~m}^{2}$ at the most recent measurement before administration of the first IV iron dose were excluded. All creatinine results reported through Alberta Health Services Analytics include the eGFR, which is calculated using the CKD-EPI (Chronic Kidney Disease Epidemiology Collaboration) equation. ${ }^{18}$

\section{Data Sources}

Patients were identified using BDM Pharmacy (BDM Healthware Inc), the dispensing software used in Calgary hospitals, which contains patients' demographic information and details about IV iron doses dispensed, including dose (mg), formulation (iron sucrose, sodium ferric gluconate, or iron dextran), date dispensed, and treatment location. The laboratory values pertinent to the inclusion and exclusion criteria and study outcomes (eGFR, Hb, MCV, and ferritin) were obtained through Alberta Health Services Analytics. Dispensing data for oral iron products, including ferrous sulfate, ferrous gluconate, ferrous fumarate, polysaccharide iron complex, and heme iron polypeptide, were obtained from the Pharmaceutical Information Network, the electronic database in Alberta that captures outpatient prescriptions and dispensed schedule II products, including the aforementioned oral iron products. Sunrise Clinical Manager (Allscripts Healthcare, LLC), the electronic medical records program used in Calgary hospitals, was used to review discharge summaries for collection of symptom data for the inpatient population.

\section{Outcomes}

Adult patients with eGFR of $30 \mathrm{~mL} / \mathrm{min} / 1.73 \mathrm{~m}^{2}$ or above who received IV iron were described in terms of pretreatment laboratory indices, including $\mathrm{Hb}, \mathrm{MCV}$, and ferritin. The proportion of patients with a previous trial of oral iron and a description of IV iron prescriptions, including formulation, doses of IV iron, and treatment setting in which they were received, were also evaluated. A previous trial of oral iron was defined as any oral iron dispensed (as documented in the Pharmaceutical Information Network) within 90 days before initiation of IV iron, as this represents a reasonable duration for trialling oral iron therapy and a typical maximum dispensing interval in Alberta. Additionally, the proportion of inpatients whose treatment was in alignment with the TOP IDA guideline treatment algorithm, based on pretreatment laboratory indices and the presence or absence of anemia symptoms, was determined. It was not feasible to report this outcome for the outpatient cohort, because the information required to determine the presence or absence of symptoms was not readily available through the selected methodology. The TOP guideline was chosen because it is current, was created locally, and has been supported by Alberta physicians and other health care providers. ${ }^{16}$ Furthermore, provincial AHS guidelines were not yet in place at the time of this study. For IV iron use to be warranted, according to this guideline, a patient must meet laboratory criteria for diagnosis (Table 1) and must have either $\mathrm{Hb}$ less than $60 \mathrm{~g} / \mathrm{L}$ or $\mathrm{Hb}$ less than $100 \mathrm{~g} / \mathrm{L}$ in combination with symptoms of anemia. ${ }^{6}$ For patients in the inpatient cohort who met the laboratory criteria for IDA diagnosis but had $\mathrm{Hb}$ between 60 and $100 \mathrm{~g} / \mathrm{L}$, discharge summaries were reviewed for the presence of symptomatic anemia, which was defined as documentation in the chart of IDA symptoms as set out in the TOP guideline treatment algorithm or synonyms of these terms or acceptable abbreviations (Table 2).

\section{Patient Characteristics and Data Collection}

Demographic data were collected for each patient, including age and sex. IV iron doses were assessed for administration location (inpatient or ambulatory), and specific treatment units were noted. Data for IV iron doses were reviewed from January 1, 2018, until the end of the study time frame to ensure that the sample included only patients who received their first dose after the release of the TOP IDA guideline in March 2018. Laboratory indices, including eGFR, Hb, MCV, and ferritin, and records of oral iron dispensed, obtained from the Pharmaceutical Information Network, were collected for all patients who met the inclusion criteria.

\section{Statistical Analysis}

Descriptive statistics were used to describe the study population and IV iron doses. Continuous variables were described using means and standard deviations (SDs) for normally distributed variables or medians and interquartile ranges (IQRs) for variables without a normal distribution. Categorical variables were expressed using frequency counts and proportions. All statistics, as well as the creation of tables and graphs, were completed using Excel 2013 (Microsoft Corporation).

TABLE 1. Laboratory Criteria for Diagnosis of Iron Deficiency Anemia, Based on the Toward Optimized Practice Clinical Practice Guideline ${ }^{6}$

\begin{tabular}{lcc}
\multirow{2}{*}{ Criterion } & \multicolumn{2}{c}{ Sex; Criterion Value } \\
\cline { 2 - 3 } & Male & Female \\
\hline Hemoglobin $(\mathrm{g} / \mathrm{L})$ & $<135$ & $<120$ \\
& Plus at least one of the following: \\
Mean corpuscular volume $(\mathrm{fL})$ & $<75$ & $<75$ \\
Ferritin $(\mu \mathrm{g} / \mathrm{L})$ & $<30$ & $<13$ \\
\hline
\end{tabular}


TABLE 2. Symptoms of Anemia, Accepted Synonyms, and Abbreviations

\begin{tabular}{ll}
\hline Symptom & Acceptable Synonyms and Abbreviations \\
\hline Shortness of breath & $\begin{array}{l}\text { Dyspnea } \\
\text { SOB }\end{array}$ \\
\hline Chest pain & $\begin{array}{l}\text { Chest discomfort } \\
\text { CP }\end{array}$ \\
\hline Light-headedness & $\begin{array}{l}\text { Fainting or feeling faint } \\
\text { Dizziness }\end{array}$ \\
Syncope & $\begin{array}{l}\text { Presyncope } \\
\text { Fainting } \\
\text { Altered, impaired, or reduced level } \\
\text { of consciousness }\end{array}$ \\
& $\begin{array}{l}\text { Hematochezia } \\
\text { Suspected ongoing } \\
\text { bleeding }\end{array}$ \\
& $\begin{array}{l}\text { Mematuria } \\
\text { Hematemesis } \\
\text { Hematoma } \\
\text { Gastrointestinal bleed (GI bleed, GIB) } \\
\text { Bleeding } \\
\text { Bleed } \\
\text { Estimated blood loss (EBL) }\end{array}$ \\
\hline
\end{tabular}

${ }^{a}$ As per treatment algorithm of Toward Optimized Practice Iron Deficiency Anemia Committee. ${ }^{6}$

\section{Ethics Approval}

Ethics approval was obtained from the Health Research Ethics Board - Health Panel of the University of Alberta, with a waiver of consent granted.

\section{RESULTS}

A total of 1616 patients had dispensing of their first dose of IV iron between March 1 and December 31, 2018, and had prior measurement of eGFR. Of these patients, 261 (16.2\%) were excluded because eGFR was less than $30 \mathrm{~mL} /$ $\min / 1.73 \mathrm{~m}^{2}$. Three additional patients were excluded after it was determined that none of their prescribed doses had been administered. A total of 1352 patients met the inclusion criteria and were included in the outcome analyses (Figure 1).

Baseline characteristics, including age, sex, treatment setting, and details of IV iron doses, are presented in Table 3. In total, $233(17.2 \%)$ patients had received oral iron within 90 days before their first IV iron dose, as indicated by listing of an oral iron product in the Pharmaceutical Information Network. Half of all IV iron doses captured were dispensed to Day Medicine departments, the majority of which were iron sucrose (Table 3).

The overall mean $\mathrm{Hb}$ concentration measured before the first IV iron infusion within the study period was 92 (SD 19.6) g/L. Of all patients, 412 (30.5\%) had pretreatment $\mathrm{Hb}$ above $100 \mathrm{~g} / \mathrm{L}$, the most frequently reported range (Figure 2). Twelve (2.6\%) of the 463 men and $112(12.6 \%)$ of the
889 women had $\mathrm{Hb}$ within normal limits, as defined in the TOP guideline ${ }^{6}$ (Table 1 ).

The mean MCV for these patients was 81 (SD 10.3) fL, and $368(27.2 \%)$ of the patients had MCV less than $75 \mathrm{fL}$, consistent with the TOP guideline criteria for diagnosis of IDA $^{6}$ (Table 1). Among the included patients, 1207 (89.3\%) had ferritin measurement before their first dose of IV iron (Figure 3), with the median value being 18 (IQR 9-48) $\mu \mathrm{g} / \mathrm{L}$. Among those with pretreatment measurement of ferritin, 588 (48.7\%) met the TOP criteria for diagnosis of IDA.

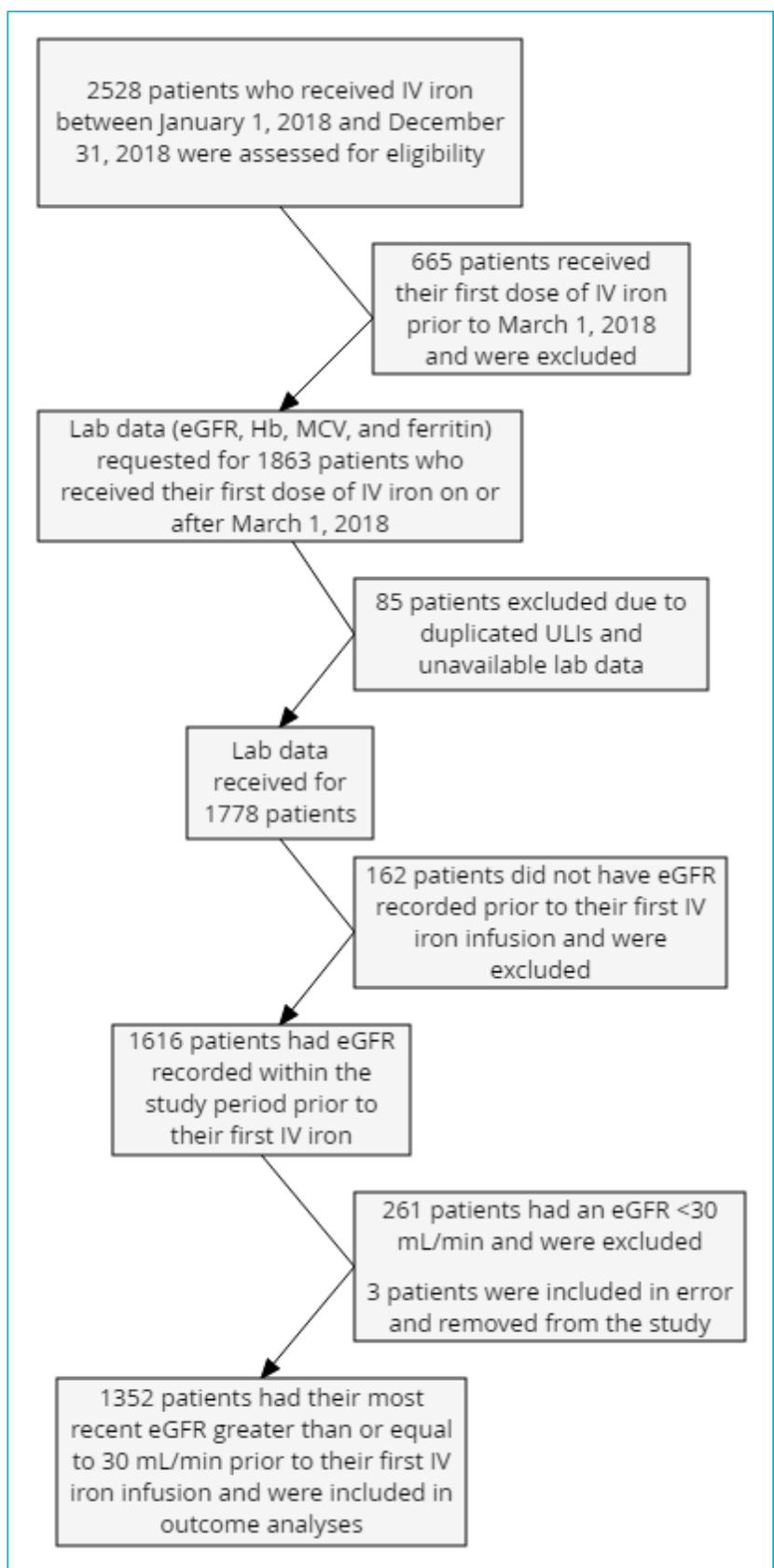

FIGURE 1. Study inclusion flow chart. eGFR = estimated glomerular filtration rate, $\mathrm{Hb}=$ hemoglobin, $\mathrm{MCV}=$ mean corpuscular volume, $U L I=$ unique lifetime identifier (standard identification number assigned to all patients receiving health care in Alberta). 


\section{TABLE 3. Baseline Characteristics and IV Iron Data}

\begin{tabular}{lcc}
\hline Characteristic & \multicolumn{2}{c}{ No. (\%) } \\
\hline Age (years) (median and IQR) & 58 & $(41-74)$ \\
\hline Sex & $n=1352$ & patients \\
Male & 463 & $(34.2)$ \\
Female & 889 & $(65.8)$ \\
\hline Patients by treatment setting & $n=1352$ & patients \\
Inpatient & 726 & $(53.7)$ \\
Outpatient & 626 & $(46.3)$ \\
\hline Doses by treatment setting & $n=3532$ doses \\
Inpatient & 1573 & $(44.5)$ \\
Outpatient & 1959 & $(55.5)$ \\
\hline Doses by IV iron formulation & $n=3532$ & doses \\
Iron sucrose & 3430 & $(97.1)$ \\
Sodium ferric gluconate complex & 102 & $(2.9)$ \\
\hline IV iron dose description & \multicolumn{3}{|c}{} \\
Mean dose per dose dispensed & \multicolumn{2}{c}{$262.5 \mathrm{mg}$} \\
Median dose per dose dispensed & \multicolumn{3}{c}{$300 \mathrm{mg}$} \\
Mean total dose dispensed per patient & $685.6 \mathrm{mg}$ \\
Mean no. of IV iron doses per patient & 2.6 doses \\
\hline
\end{tabular}

$\mathrm{IQR}=$ interquartile range.

${ }^{a}$ Except where indicated otherwise.

Overall, the TOP laboratory criteria for IDA diagnosis, based on $\mathrm{Hb}, \mathrm{MCV}$, and ferritin (Table 1), ${ }^{6}$ were fulfilled by $648(47.9 \%)$ of the included patients. Of the 726 patients in the inpatient cohort, 146 (20.1\%) had either Hb below $100 \mathrm{~g} / \mathrm{L}$ and documented symptoms of anemia or Hb below $60 \mathrm{~g} / \mathrm{L}$, thus warranting the use of IV iron according to the TOP guideline. The proportions of patients meeting the diagnostic criteria and receiving IV iron according to guideline parameters were similar for men and women. For 7 inpatients, no discharge summary was available, and it could not be confirmed whether their treatment was in alignment with TOP recommendations.

\section{DISCUSSION}

In Calgary, the increasing utilization of IV iron has raised drug expenditures and reduced clinic capacity. This increase in IV iron utilization may be explained in part by recent initiatives to support appropriate use of red blood cell transfusions. For example, recent Choosing Wisely recommendations include avoiding transfusions in hemodynamically stable patients with IDA, with consideration of iron replacement instead. ${ }^{16}$ When appropriate, IV iron products are a safe and less expensive alternative to blood transfusions; however, the acquisition cost for IV iron products and the resources required for their preparation, administration, and monitoring are significantly greater than those required for oral iron. Furthermore, given the limited availability of appointments in Day Medicine departments and frequent

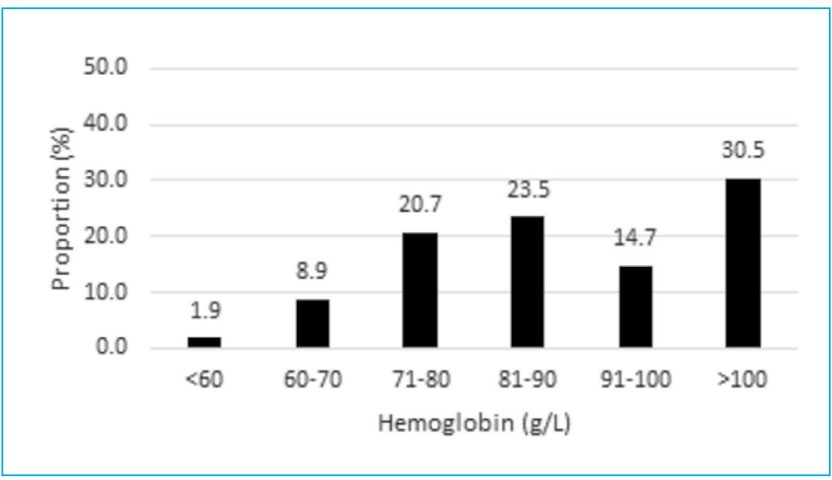

FIGURE 2. Distribution of hemoglobin values among patients who had measurement of hemoglobin before the first iron infusion (within the study time frame) $(n=1351)$.

drug shortages, overprescribing can hinder access for those who more urgently require IV iron or space in Day Medicine for other treatments.

The TOP guideline proposes $\mathrm{Hb}, \mathrm{MCV}$, and ferritin as the criteria for laboratory diagnosis and monitoring of IDA, consistent with recommendations elsewhere in the literature. ${ }^{1,4-7,9}$ In this study, approximately half of the patients for whom IV iron was prescribed met the laboratory criteria for diagnosis of IDA. These results suggest that these laboratory indices and/or the criteria in the TOP guideline are not being consistently applied in the diagnosis and treatment of IDA in Calgary and that there may be significant room for optimizing the use of IV iron. Although the method used did not take into account other indications for IV iron, such as malabsorption syndromes and blood loss exceeding the absorptive capacity of iron, it is unlikely that these conditions would make up for the large discrepancy between the guideline and clinical use. When each laboratory parameter was evaluated individually, the majority of patients had $\mathrm{Hb}$ meeting the suggested criteria, whereas fewer than half met the criteria for MCV and ferritin (Table 1). Furthermore, only 1207 of the 1352 patients had ferritin levels measured

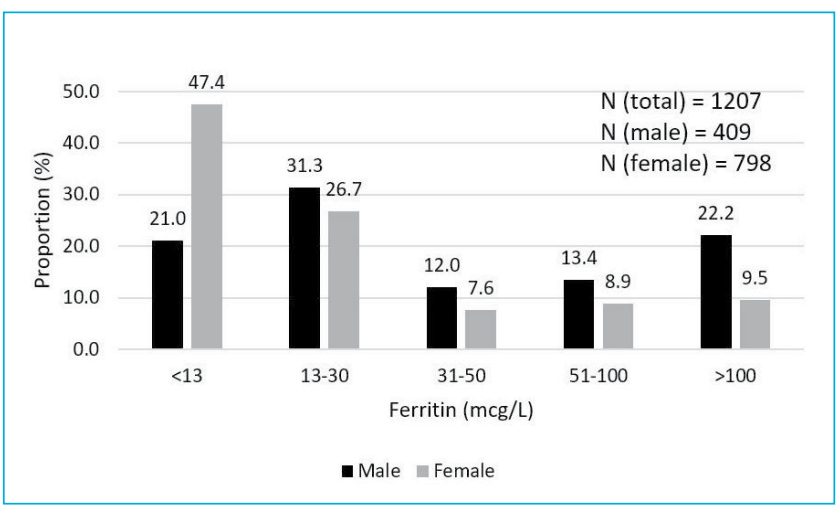

FIGURE 3. Distribution of ferritin values among patients who had measurement of ferritin before the first iron infusion (within the study time frame) ( $n=1207)$. 
before their first IV iron infusion, which highlights the potential for a more comprehensive use of ferritin before IV iron is initiated.

The existing literature describing appropriate IV iron utilization is sparse and often limited to studies with small sample sizes. A 2007 audit of iron utilization in the Ulster Hospital, Northern Ireland, evaluated 47 patients who received IV iron and determined that $45 \%$ were not treated according to local guidelines. ${ }^{19}$ A small prospective study in the AHS South Zone in 2017 evaluated 17 patients who received IV iron; 6 (35\%) of these patients were not treated according to prespecified criteria (Barnson C, Fong V. A snapshot of intravenous iron infusions at Chinook Regional Hospital [CRH] and eight surrounding rural sites over a five day time period; unpublished report). Of the 726 inpatients in the current study, only 146 (20.1\%) were treated in alignment with the TOP guideline. This result was limited by the retrospective study design, which allowed evaluation of laboratory data and discharge summaries only; however, given the low rates described with these limited data, it is possible that prescribing is infrequently concordant with guidelines.

Another factor that may be considered when prescribing IV iron is whether there has been an adequate trial of oral iron in the past. In the current study, Pharmaceutical Information Network profiles for the majority of patients showed no record of oral iron within 90 days before the first IV iron dose. It is difficult to interpret this result, because these profiles capture information only for schedule II oral iron products provided in the community pharmacy setting, with no information about adherence, duration of use, or provision of oral iron in the inpatient setting. This study suggests that IV administration of iron is being prescribed regardless of whether an oral iron product has been trialled previously; further study is required to confirm this finding.

Although pregnancy status was not captured, the proportion of women of child-bearing age within the study sample was substantially greater than the proportion of men in the same age group (Figure 4). This is likely because of higher iron requirements and the prevalence of IDA in menstruating and pregnant women. ${ }^{6,9}$ Iron supplementation is often recommended for pregnant women, because maternal IDA may increase the risk of preterm delivery, low birth weight, ${ }^{6,10}$ and, in severe cases, increased maternal and neonatal mortality. ${ }^{10}$ However, pregnancy alone does not always necessitate the preferential use of IV iron over oral formulations. A 2019 systematic review and meta-analysis comparing IV and oral administration of iron to pregnant women showed that IV administration was associated with statistically significant but modest increases in maternal $\mathrm{Hb}$ and ferritin at delivery and in birth weight; however, the clinical relevance of these results remains in question, and data on other important clinical outcomes are limited. ${ }^{20}$

This study was limited by the use of retrospective data from electronic sources, which precluded a more accurate evaluation of each patient's history, symptoms, specific IV iron indication, and comorbidities. Additionally, IV iron dispensed to Day Medicine departments at 2 of the included hospitals could not be analyzed because parenteral iron is prepared using ward stock at these sites; therefore, doses could not be attributed to specific patients using the BDM Pharmacy software. As a result, ambulatory patients were underrepresented in this study relative to inpatients. Furthermore, the use of blood products was not evaluated. Patients in this study might have received transfusions before the first IV iron infusion, which may have modified laboratory markers for anemia and affected the categorization of study results. Thus, evaluating the appropriateness of IDA management, including transfusion medicine and the use of iron products, remains an important topic for future research. With regard to previous use of oral iron, limiting the fill dates for oral iron to 90 days before a patient's first IV iron dose might have resulted in underestimation of patients who had previously trialled oral iron if this form of therapy was tried and failed before this time frame. Additionally, there is a possibility that not all of the oral iron dispensed was captured by the Pharmaceutical Information Network. Finally, the TOP IDA guideline is intended for use in emergency departments and primary care settings; as such, using this guideline to

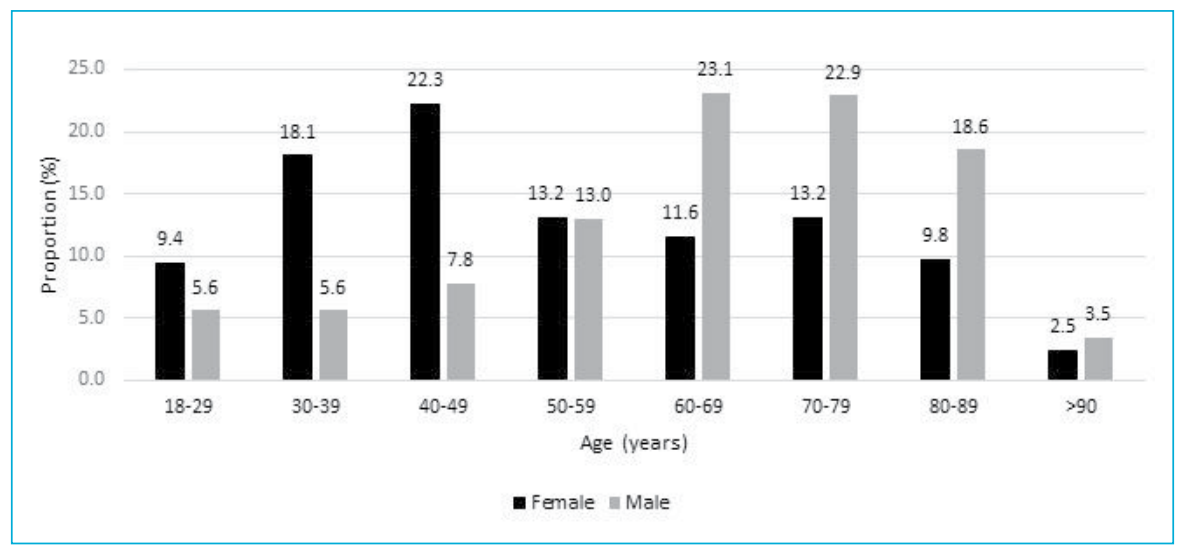

FIGURE 4. Age distribution of included patients $(n=1352)$. 
evaluate the appropriateness of IV iron prescribing for inpatients is not optimal. ${ }^{6}$ However, a local guideline more suitable for this population was not available.

\section{CONCLUSION}

The results presented here suggest that the use of IV iron in the study jurisdiction was often not aligned with guidelines, including laboratory and clinical criteria for this type of therapy. A potential strategy to promote consistency of diagnosis and treatment would be for the province to adopt a single guideline, such as the TOP guideline, with concomitant provision of practice tools incorporating TOP recommendations to optimize iron prescribing. The creation of a central iron clinic, with multidisciplinary teams to evaluate parenteral iron referrals for appropriateness before administration of the first dose, has also been proposed. ${ }^{16}$ Formulary restriction of IV iron products to patients meeting prespecified criteria, based on relevant laboratory tests, comorbidities, and previous use of oral iron may also be considered. Implementing such strategies will require collaboration among multidisciplinary stakeholders across the province to ensure that implemented measures improve the cost-effective use of iron products and access to outpatient Day Medicine programs, without creating barriers to parenteral iron products for those who require them. Further research is needed to fully characterize the treatment of IDA in other jurisdictions and across various specialties to ensure effective stewardship of the resources used to manage this common condition.

\section{References}

1. Iron deficiency anemia. In: In-depth answers. Micromedex. Truven Health Analytics; 2018 [cited 2018 Jul 18]. Available from: www. micromedexsolutions.com. Subscription required to access content.

2. Iron deficiency anemia in adults. In: Dynamed Plus. EBSCO Information Services; 2018 [cited 2018 Jul 18]. Available from: https:// www-dynamed-com.ahs.idm.oclc.org/topics/dmp AN T115986/. Subscription required to access content.

3. Lim W. Common anemias. In: Therapeutics. Canadian Pharmacists Association; 2018 [cited 2018 Jul 18]. Available from: http://www. myrxtx.ca. Subscription required to access content; also available in hard copy from the publisher.

4. Peyrin-Biroulet L, Williet N, Cacoub P. Guidelines on the diagnosis and treatment of iron deficiency across indications: a systematic review. Am J Clin Nutr. 2015;102(6):1585-94.

5. Short MW, Domagalski JE. Iron deficiency anemia: evaluation and management. Am Fam Physician. 2013;87(2):98-104.

6. Toward Optimized Practice Iron Deficiency Anemia Committee. Iron deficiency anemia (IDA) clinical practice guideline. Toward Optimized Practice; 2018 Mar [cited 2020 Nov 17]. Available from: https://actt. albertadoctors.org/CPGs/Lists/CPGDocumentList/IDA-CPG.pdf

7. Clark SF. Iron deficiency anemia. Nutr Clin Pract. 2008;23(2):128-41.

8. Oral iron for anemia: a review of the clinical effectiveness, cost-effectiveness and guidelines [rapid response report]. Canadian Agency for Drugs and Technologies in Health; 2016 [cited 2018 Sep 30]. Available from: http://www.ncbi.nlm.nih.gov/books/NBK343969/
9. Lopez A, Cacoub P, Macdougall IC, Peyrin-Biroulet L. Iron deficiency anaemia. Lancet. 2016;387(10021):907-16.

10. Camaschella C. Iron-deficiency anemia. N Engl J Med. 2015;372(19): 1832-43.

11. Silverstein SB, Gilreath JA, Rodgers GM. Intravenous iron therapy: a summary of treatment options and review of guidelines. J Pharm Pract. 2008;21(6):431-43.

12. Auerbach $M$, Macdougall I. The available intravenous iron formulations: history, efficacy, and toxicology. Hemodial Int. 2017;21 Suppl 1: S83-92.

13. Gurusamy KS, Nagendran M, Broadhurst JF, Anker SD, Richards T. Iron therapy in anaemic adults without chronic kidney disease. Cochrane Database Syst Rev. 2014;(12):CD010640.

14. Clevenger B, Gurusamy K, Klein AA, Murphy GJ, Anker SD, Richards T. Systematic review and meta-analysis of iron therapy in anaemic adults without chronic kidney disease: updated and abridged Cochrane review. Eur J Heart Fail. 2016;18(7):774-85.

15. Rozen-Zvi B, Gafter-Gvili A, Paul M, Leibovici L, Shpilberg O, Gafter U. Intravenous versus oral iron supplementation for the treatment of anemia in CKD: systematic review and meta-analysis. Am J Kidney Dis. 2008;52(5):897-906.

16. Iron summit conference report. Alberta Health Services, University of Calgary, Choosing Wisely Canada; 2017 [cited 2018 Jul 19]. Available from: https://cumming.ucalgary.ca/sites/default/files/teams/127/ iron-summit-conference-report.-2017.pdf

17. A healthier future. Together. Alberta Health Services annual report 2017-18. Alberta Health Services; 2018 [cited 2019 May 6]. Available from: www.ahs.ca

18. Levey AS, Stevens LA, Schmid CH, Zhang YL, Castro AF 3rd, Feldman HI, et al. A new equation to estimate glomerular filtration rate. Ann Intern Med. 2009;150(9):604-12.

19. Ghebeh M, Qedai F, El-Agnaf M, Ong Y. Audit of intravenous iron usage in the Ulster Hospital [abstract]. Br J Haematol. 2009;145 Suppl:55-6.

20. Lewkowitz AK, Gupta A, Simon L, Sabol BA, Stoll C, Cooke E, et al Intravenous compared with oral iron for the treatment of iron-deficiency anemia in pregnancy: a systematic review and meta-analysis. J Perinatol. 2019;39(4):519-32.

Thomas Brownlee, BSP, ACPR, is with Red Deer Regional Hospital Centre, Red Deer, Alberta.

Deonne Dersch-Mills, BScPharm, ACPR, PharmD, is with Alberta Health Services - Pharmacy Services, Calgary, Alberta.

Ginny Cummings, BScPharm, ACPR, is with Alberta Health Services Pharmacy Services, Calgary, Alberta.

Tanya Fischer, BScPharm, is with Alberta Health Services - Pharmacy Services, Edmonton, Alberta.

Rhonda Shkrobot, BScPharm, ACPR, is with Alberta Health Services Pharmacy Services, Edmonton, Alberta.

Jeremy Slobodan, BSP, is with Alberta Health Services - Pharmacy Services, Red Deer, Alberta.

Jenny Wichart, BScPharm, ACPR, is with Alberta Health Services - Pharmacy Services, Calgary, Alberta.

Competing interests: None declared.

Address correspondence to:

Thomas Brownlee

Red Deer Regional Hospital Centre

3942 50a Avenue

Red Deer AB T4N 4E7

email: thomas.brownlee@ahs.ca

Funding: None received. 